\title{
An evaluation of ASCAT surface soil moisture products with in-situ observations in Southwestern France
}

\author{
C. Albergel ${ }^{1}$, C. Rüdiger ${ }^{1}{ }^{*}$, D. Carrer ${ }^{1}$, J.-C. Calvet ${ }^{1}$, N. Fritz ${ }^{1}$, V. Naeimi ${ }^{2}$, Z. Bartalis ${ }^{2}$, and S. Hasenauer ${ }^{2}$ \\ ${ }^{1}$ CNRM/GAME (Météo-France, CNRS), Toulouse, France \\ ${ }^{2}$ Institute of Photogrammetry and Remote Sensing, University of Vienna, Vienna, Austria \\ *now at: Department of Civil and Environmental Engineering, The University of Melbourne, Melbourne, Australia
}

Received: 7 July 2008 - Published in Hydrol. Earth Syst. Sci. Discuss.: 11 August 2008

Revised: 5 December 2008 - Accepted: 21 December 2008 - Published: 4 February 2009

\begin{abstract}
A long term data acquisition effort of profile soil moisture is currently underway at 13 automatic weather stations located in Southwestern France. In this study, the soil moisture measured in-situ at $5 \mathrm{~cm}$ is used to evaluate the normalised surface soil moisture (SSM) estimates derived from coarse-resolution $(25 \mathrm{~km})$ active microwave data of the ASCAT scatterometer instrument (onboard METOP), issued by EUMETSAT for a period of 6 months (April-September) in 2007. The seasonal trend is removed from the satellite and in-situ time series by considering scaled anomalies. One station (Mouthoumet) of the ground network, located in a mountainous area, is removed from the analysis as very few ASCAT SSM estimates are available. No correlation is found for the station of Narbonne, which is close to the Mediterranean sea. On the other hand, nine stations present significant correlation levels. For two stations, a significant correlation is obtained when considering only part of the ASCAT data. The soil moisture measured in-situ at those stations, at $30 \mathrm{~cm}$, is used to estimate the characteristic time length $(T)$ of an exponential filter applied to the ASCAT product. The best correlation between a soil water index derived from ASCAT and the in-situ soil moisture observations at $30 \mathrm{~cm}$ is obtained with a $T$-value of 14 days.
\end{abstract}

\section{Introduction}

Soil moisture plays a key role in the interactions between the hydrosphere, the biosphere and the atmosphere, as its controls both evaporation and transpiration from bare soil and

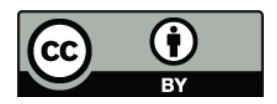

Correspondence to: J.-C. Calvet (calvet@meteo.fr) vegetated areas, respectively. For many applications, global or continental scale soil moisture maps are needed. A number of studies have been conducted or are currently underway to obtain soil moisture estimates from spaceborne microwave instruments (Wagner et al., 1999a, b, c; Kerr et al., 2001; Njoku et al., 2003). Indeed, microwave remote sensing is able to provide quantitative information about the water content of a shallow near surface layer (Schmugge, 1983), particularly in the low-frequency microwave region from 1 to $10 \mathrm{GHz}$.

L-band is the optimal wavelength range to observe soil moisture. Higher frequencies are more significantly affected by perturbing factors such as atmospheric effects and vegetation cover (Schmugge, 1983; Kerr et al., 2001). Apart from a few days of L-band radiometric observations on Skylab from June 1973 to January 1974 (Jackson et al., 2004), current or past instruments have been operating at frequencies above $5 \mathrm{GHz}$, because (i) lower frequencies are a technical challenge to perform; the satellite antenna size is directly proportional to the squared wavelength (Ulaby et al., 1982), (ii) these instruments were not dedicated to soil moisture missions.

The SMOS project (Soil Moisture and Ocean Salinity, ESA/CNES), scheduled for launch in 2009, consists of developing a spaceborne L-band $(1.423 \mathrm{GHz}, 21 \mathrm{~cm})$ interferometric radiometer able to provide global estimates of surface soil moisture (SSM) with a sampling time step of $2-3$ days. It is the first satellite designed for measuring soil moisture over land (Kerr et al., 2001, 2007). Previous spaceborne microwave radiometers were the Scanning Multichannel Microwave Radiometer (SMMR) which operated on Nimbus7 between 1978 and 1987 at $6.6 \mathrm{GHz}$ and above, followed by the Special Sensor Microwave Imager (SSM/I starting

Published by Copernicus Publications on behalf of the European Geosciences Union. 
in 1987), at $19 \mathrm{GHz}$ and above. Instruments currently operational at frequencies close to the L-band are the Advanced Microwave Scanning Radiometer for the Earth Observing System (AMSR-E on the Aqua satellite), WindSAT (a satellite-based polarimetric microwave radiometer on the Coriolis satellite), the scatterometer on board the European Remote Sensing Satellite (ERS-1, ERS-2), and now ASCAT (Advanced Scatterometer) on METOP (launched in 2006) with a spatial resolution of circa $50 \mathrm{~km}$ (products are resampled to a $25 \mathrm{~km}$ grid in the swath geometry) or ca. $30 \mathrm{~km}$ (in this case, products are resampled to a $12.5 \mathrm{~km}$ grid in the swath geometry) at $5.255 \mathrm{GHz}$ (C-Band) (Wagner et al., 2007a; Bartalis et al., 2007a, b).

Soil moisture products are derived from these microwave remote sensing observations and they need to be verified through in-situ soil moisture observations (Rüdiger et al., 2009). Relatively few in-situ soil moisture networks are operative now. Soil moisture observations are available through the Global Soil Moisture Data Bank (Robock et al., 2000). More recently, a number of soil moisture networks were developed, e.g. the Goulburn River experimental catchment in Australia (Rüdiger et al., 2007) or SMOSMANIA (Soil Moisture Observing System - Meteorological Automatic Network Integrated Application, Calvet et al., 2007; Albergel et al., 2008) in Southwestern France.

In this study, the first ASCAT data products covering a period of six months from April to September 2007 (data are from the commissioning phase, produced by EUMETSAT) are compared with in-situ observations. For this purpose the SMOSMANIA network is used. It is a long-term data acquisition effort of profile soil moisture observations in Southwestern France. The SMOSREX (Surface Monitoring Of the Soil Reservoir EXperiment) experimental site (De Rosnay et al., 2006) located close to a number of SMOSMANIA stations, is used, as SMOSREX also provides profile soil moisture measurements.

The ASCAT SSM retrievals are based on a change detection approach, originally developed for the active microwave instrument flown onboard the European satellites ERS-1 and ERS-2 (Bartalis et al., 2007a).

In this paper, after a description of the ASCAT surface soil moisture product, a recursive exponential filter formulation which allows to estimate the SWI (Soil Water Index) from intermittent SSM measurements (Albergel et al., 2008) is presented. The SMOSMANIA network and the SMOSREX station are briefly described. Then, ASCAT products are compared with the in-situ soil moisture observations at $5 \mathrm{~cm}$. SWI estimates are derived from ASCAT and are compared with in-situ soil moisture observations at $30 \mathrm{~cm}$.

\section{Material and methods}

\subsection{The ASCAT SSM product}

Like ERS-1 and ERS-2 scatterometers, ASCAT is a realaperture radar instrument measuring radar backscatter with very good radiometric accuracy and stability (Bartalis et al., 2007a). ASCAT uses a VV polarization in the C-band $(5.255 \mathrm{GHz})$ and observes the surface of the Earth with a spatial resolution of circa $50 \mathrm{~km}$ or $30 \mathrm{~km}$. In this study, the $50 \mathrm{~km}$ product (resampled to a $25 \mathrm{~km}$ grid) is used. Measurements occur on both sides of the subsatellite track, thus two $550 \mathrm{~km}$ wide swaths of data are produced. Because ASCAT operates continuously, more than twice of the ERS scatterometer coverage is provided. On both sides of METOP, ASCAT produces a triplet of backscattering coefficients $\left(\sigma^{0}\right)$ from the three different antenna beams. A $\sigma^{0}$ measurement is the result of averaging several radar echoes. Measurements are made at $45^{\circ}, 90^{\circ}$ and $135^{\circ}$ azimuth angles (fore, mid and aft antenna beams) with respect to the satellite track. The fore and aft beam measurements are made under equal ranges of incidence angles, while the mid-beam measurements have a slightly lower range of incidence angles. Backscatter is registered at various incidence angles and it is possible to determine the yearly cycle of the backscatter incidence angle relationship. This is an essential prerequisite for correcting seasonal vegetation effects (Bartalis et al., 2007a, b; Gelsthorpe et al., 2000).

The spatial and temporal behaviour of the scatterometer is affected by land cover and vegetation phenology. It was demonstrated that by using a time series-based approach for the soil moisture retrieval, the influence of the vegetation could be minimized (Wagner et al., 1999b). In order to retrieve surface soil moisture, Wagner (1999b) proposed to scale the backscattering coefficient extrapolated to a reference angle at $40^{\circ}, \sigma^{0}(40)$, using the lowest and highest values of $\sigma^{0}(40)$ measured over a long period. They are respectively denoted $\sigma_{\text {dry }}^{0}(40, t)$ and $\sigma_{\text {wet }}^{0}(40, t)$, where $t$ is time. The theoretical background of this method is described in detail in Wagner et al. (1999a, b, c). The lowest and highest values of $\sigma^{0}(40)$ required for the processing are derived from the analysis of multi annual backscatter time series using ERS data from August 1991 to May 2007 (Bartalis et al., 2007b).

According to Wagner et al. (1999b), the surface soil moisture content $m s$ is expressed by Eq. (1).

$m s(t)=\frac{\sigma^{0}(40, t)-\sigma_{\mathrm{dry}}^{0}(40, t)}{\sigma_{\mathrm{wet}}^{0}(40, t)-\sigma_{\mathrm{dry}}^{0}(40, t)}$

Equation (1) is applied only if the ground is not frozen. The $m s$-value is a relative measure of the soil moisture content in the first few centimetres of the soil which are sensed by Cband microwaves. According to Schmugge (1983), the depth of this layer is about 0.5 to $2 \mathrm{~cm}$. Thus, $m s$ represents the degree of saturation of the topmost soil layer and is given in 
percent ranging from 0 (dry) to $100 \%$ (wet). This measure is complemented by its noise, derived by error propagation of the backscatter noise (ranging from 0 to $100 \%$, covering instrument noise, speckle and azimuthal effects). Measurements are generally obtained twice a day, in the morning (descending orbit) and at the end of the afternoon (ascending orbit), between 08:00-11:00 and 17:00-21:00 UTC, respectively, for Western Europe. Figure 1 presents an ASCAT swath over France, covering the SMOSMANIA network and SMOSREX.

\subsection{The exponential filter}

A simple method based on an exponential filter has been developed by Wagner (1999a) in order to relate intermittent surface estimates to the profile soil moisture content (Eq. 2).

$\operatorname{SWI}\left(t_{n}\right)=\frac{\sum_{i}^{n} m s\left(t_{i}\right) e^{-\frac{t_{n}-t_{i}}{T}}}{\sum_{i}^{n} e^{-\frac{t_{n}-t_{i}}{T}}}$

SWI is the Soil Water Index and $m s\left(t_{i}\right)$ is the surface soil moisture estimated from remote sensing at time $t_{i}$. T represents the time scale of soil moisture variation, in units of day.

In a previous study, Albergel et al. (2008) used a recursive formulation of Eq. (2) described by Stroud (1999) to compute the SWI. In the case of soil moisture, the following recursive equation can be written:

$\mathrm{SWI}_{n}=\mathrm{SWI}_{n-1}+K_{n}\left(m s\left(t_{n}\right)-\mathrm{SWI}_{n-1}\right)$

where the gain $K$ at time $t_{n}$ is given by:

$$
K_{n}=\frac{1}{1+\sum_{i}^{n-1} e^{-\frac{\left(t_{n}-t_{i}\right)}{T}}}
$$

This gain may also be written in a recursive form as:

$$
K_{n}=\frac{K_{n-1}}{K_{n-1}+e^{-\frac{\left(t_{n}-t_{n-1}\right)}{T}}}
$$

The range of the gain $K$ is [0,1]. In the presence of extensive temporal data gaps (relative to the filter time scale), Eq. (5) tends toward unity. In that particular case, the previous estimates are disregarded when new observations are obtained and the new estimate takes on the value of the new observation. For the initialisation of this filter, $K_{1}$ and $\mathrm{SWI}_{1}$ were set to 1 and $m s\left(t_{1}\right)$, respectively.

The ASCAT SSM product, the $m s$-values, are used through the recursive formulation of the exponential filter (Eq. 3) for SWI retrieval. In this study, the $m s$-values and the SWI are compared to in situ soil moisture measurements at depths of $5 \mathrm{~cm}$ and $30 \mathrm{~cm}$, respectively.

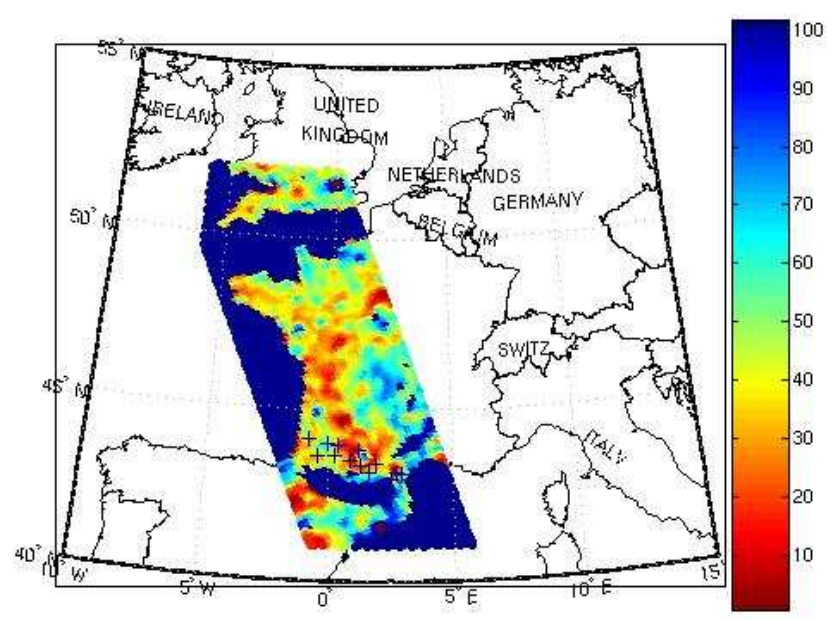

Fig. 1. An example of ASCAT surface soil moisture swath over France: ascending (p.m.) orbit of 5 April 2007. The scaled SSM values range from 0 (dry) to 100 (wet). The "+" symbols are for the twelve stations of the SMOSMANIA network and SMOSREX.

\subsection{SMOSMANIA}

The main objective of SMOSMANIA is to verify remotely sensed and modelled soil moisture products. The SMOSMANIA network is based on the existing RADOME (Réseau d'Acquisition de Données d'Observations Météorologique Etendu) automatic weather station network of Météo-France. The RADOME stations measure air temperature and humidity, wind speed and precipitation. At some stations the downwelling shortwave radiation is also measured. Twelve existing stations of RADOME were chosen in Southwestern France, in order to achieve a Mediterranean-Atlantic transect following the marked climatic gradient between the two coastlines. The main innovation of SMOSMANIA is the use of soil moisture probes in conjunction with an operational weather station network. Four soil moisture probes (ThetaProbe ML2X of Delta-T Devices ${ }^{(}{ }^{\text {) }}$ ) were installed, per station. The 4 probes form a profile at the depths of 5, 10, 20, $30 \mathrm{~cm}$. These probes are set to perform measurements at regular intervals of $12 \mathrm{~min}$. They have been installed in 2006 so that data covering the whole 2007 annual cycle are available. For this study, surface soil measurements $(5 \mathrm{~cm})$ were used. During the installation of the soil moisture probes, soil samples were collected, at the 4 depths of the soil moisture profile $(5,10,20,30 \mathrm{~cm})$. Soil texture, soil organic matter and bulk density of the soil samples were determined in the laboratory (Calvet et al., 2007; Albergel et al., 2008).

\subsection{SMOSREX}

Located at the ONERA (Office National d'Etudes et de Recherches Aérospatiales) site of Fauga-Mauzac, near Toulouse, in Southwestern France, the SMOSREX experiment (De Rosnay et al., 2006) aims at improving the 


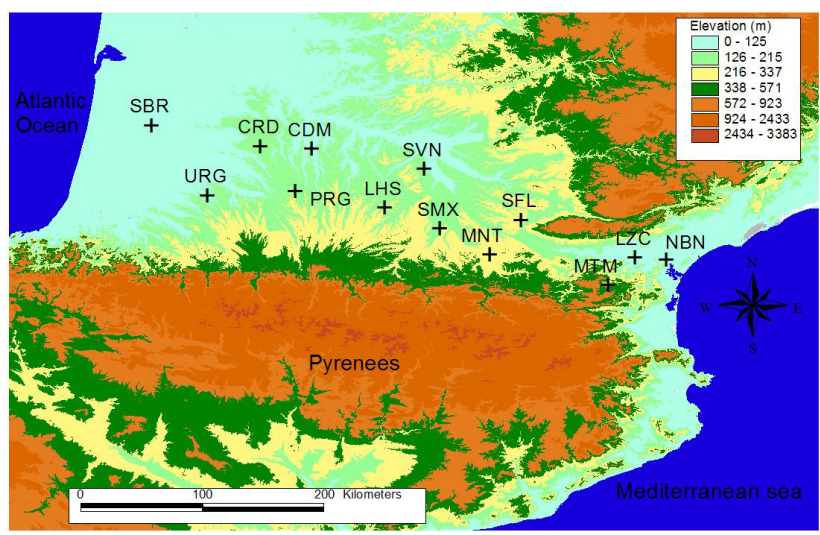

Fig. 2. The SMOSMANIA network and the SMOSREX station in South-Western France. Elevation is also presented thanks to a digital elevation model, $90 \mathrm{~m}$ from CGIAR CSL, http://srtm.csi.cgiar. org.

modelling of the microwave L-band emission of the soilvegetation system as well as improving the understanding of soil-plant-atmosphere interactions. It is an experimental site for the observation of soil moisture observation, in-situ and remotely sensed. Soil moisture measurements are taken at depths of 0 to $6 \mathrm{~cm}, 10,20,30,40,50,60,70,80,90 \mathrm{~cm}$ and are available from January 2001 to December 2007 with an half-hourly time step. For the purpose of this study, surface soil measurements $(0-6 \mathrm{~cm})$ were used.

Figure 2 presents a map of Southwestern France showing the location of the soil measurements stations with names. A precise digital elevation model $(90 \mathrm{~m}$ from CGIAR CSL, http://srtm.csi.cgiar.org) is used.

For each station, the soil moisture data are normalized by the minimal and maximal values (based on a one year cycle for the SMOSMANIA network and over the 2001-2007 period for SMOSREX).

2.5 Comparison of ASCAT soil moisture products with insitu observations

For all the stations of the SMOSMANIA network and for SMOSREX, the coordinates (latitude, longitude) of the ASCAT soil moisture grid points are compared with the station coordinates. For each satellite track the nearest grid point where an observation is available within a $7 \mathrm{~km}$ radius from the considered station is conserved. Each measurement is identified by its coordinates and the time of the satellite track, and compared with the in-situ soil moisture $(5 \mathrm{~cm})$ at the same time $( \pm 1 \mathrm{~h})$. For this study, a.m. (descending orbits) and p.m. (ascending orbits) swaths are analysed separately. This separation follows the findings by Wagner et al. (1999a, 2007b) that best correlations are found with ERS Scatterometer data from the morning passes.

For each station, correlation, bias, RMSE, Kendall statistics $(\tau)$ and $p$-value (a measure of the correlation signifi- cance), are calculated. The Kendall $\tau$ is a non-parametric measure of correlation that assesses how well an arbitrary monotonic function could describe the relationship between two variables, without making any assumptions about the frequency distribution of the variables. It is used to measure the degree of correspondence between two rankings and to assess the significance of this correspondence. The $p$-value indicates the significance of the test, if it is small (e.g. below 0.05), it means that the correlation is not a coincidence. In this study, the following thresholds on $p$-values are used: (i) NS (non significant) for $p$-value greater than 0.05 , (ii) * between 0.05 and 0.01 , (iii) ** between 0.01 and 0.001 , (iv) $* * *$ between 0.001 and 0.0001 and $(\mathrm{v}) * * * *$ below a value of 0.0001 .

In order to avoid seasonal effects, monthly anomalies were also calculated. The difference to the mean is calculated for a sliding window of five weeks (if there are at least five measurements in this period), and the difference is scaled to the standard deviation. For each ASCAT estimate $m s$ at day $(i)$, a period $F$ is defined, with $F=[i-17 d, i+17 d]$ (corresponding to a 5-week window). If at least five measurements are available in this period of time, the average ASCAT value and the standard deviation are calculated. The anomaly $A$ is dimensionless. It is given by:

$$
A(i)=\frac{m s(i)-\overline{m s(F)}}{\operatorname{Stdev}(m s(F))}
$$

The same equation is used to compute in-situ anomalies, which can be compared with the ASCAT SSM anomalies.

\section{Analysis of the results}

\subsection{Comparison of the time series}

Statistical scores for the comparison between ASCAT products and normalized in-situ soil moisture were determined both as a function of the location of the ASCAT grid with respect to the station (ASCAT grid points at north, south, west or east) and for the pooled ASCAT grid points. They are presented in Table 1 for descending orbits (a.m.) only. The location-dependent correlation between ground and ASCAT SSM permits to characterise the representativeness of the ground stations and of the ASCAT product. One station of the SMOSMANIA network, MTM, located in a rather mountainous area (538 m a.s.l.) is not used because of the lack of satellite measurements (only three SSM retrieved values are available for the April-September 2007 period).

Statistical scores for ascending orbits (p.m.) were also calculated (not shown). Most often than not, high p-values indicate that the test is not significant. For few stations, the test is significant, however, the correlations are low. An explanation could be a decoupling developing at daytime between the soil moisture of the thin soil layer sampled by ASCAT $(\sim 0.5-2 \mathrm{~cm})$ and the deeper layer $(5 \mathrm{~cm})$ observed at 
Table 1. Comparison between ASCAT products and the scaled in-situ soil moisture $(5 \mathrm{~cm})$ measured at 12 ground stations, for descending (morning) orbits between 1 April and 30 September 2007: correlation coefficient, bias (in-situ minus ASCAT), root mean square error (RMSE), and Kendall statistics (correlation $\tau$, and $p$-value). The scores are presented for either all the ASCAT observations or for separate subsets (higher vs. lower latitude (longitude) of the ground station, noted North and South (West and East)). The number of data used to calculate the scores is given.

\begin{tabular}{|c|c|c|c|c|c|c|c|c|c|c|c|c|c|c|c|c|c|c|c|c|c|c|c|c|c|c|c|c|c|c|}
\hline \multirow{2}{*}{$\begin{array}{l}\text { Station } \\
\text { Direction }\end{array}$} & \multicolumn{5}{|c|}{$\begin{array}{c}\text { Number of ASCAT } \\
\text { data available }\end{array}$} & \multicolumn{5}{|c|}{ Correlation } & \multicolumn{5}{|c|}{ Bias } & \multicolumn{5}{|c|}{ RMSE } & \multicolumn{5}{|c|}{ Kendall tau } & \multicolumn{5}{|c|}{ Kendall $p$-value } \\
\hline & $\mathrm{N}$ & $\mathrm{W}$ & E & $\mathrm{s}$ & All | & $\mathrm{N}$ & w & E & $\mathrm{s}$ & All & $\mathrm{N}$ & w & E & $\mathrm{s}$ & All & $\mathrm{N}$ & $\mathrm{w}$ & E & $\mathrm{s}$ & All & $\mathrm{N}$ & $\mathrm{w}$ & E & $\mathrm{s}$ & All & $\mathrm{N}$ & $\mathrm{w}$ & E & $\mathrm{s}$ & All \\
\hline Sabres (SBR) & 25 & 29 & 23 & 27 & 52 & 0.559 & 0.619 & 0.626 & 0.616 & 0.616 & -0.254 & 0.253 & 0.280 & -0.276 & -0.265 & 0.304 & 0.289 & 0.329 & 0.311 & 0.307 & $* * *$ & $* * *$ & $* * *$ & $* * *$ & $* * * *$ & 0.523 & 0.472 & 0.501 & 0.484 & 0.508 \\
\hline Urgons (URG) & 20 & 19 & 17 & 16 & 36 & 0.701 & 0.775 & 0.687 & 0.787 & 0.732 & -0.054 & -0.042 & 0.023 & 0.033 & -0.013 & 0.196 & 0.173 & 0.193 & 0.165 & 0.182 & $* * *$ & $* * *$ & $*$ & $* *$ & $* * * *$ & 0.437 & 0.541 & 0.398 & 0.532 & 0.475 \\
\hline Creon (CRD) & 31 & 26 & 28 & 23 & 54 & 0.594 & 0.549 & 0.651 & 0.662 & 0.603 & -0.264 & -0.272 & -0.302 & -0.319 & -0.288 & 0.315 & 0.320 & 0.337 & 0.347 & 0.329 & $* * *$ & *** & $* * *$ & *** & $* * * *$ & 0.455 & 0.424 & 0.470 & 0.458 & 0.453 \\
\hline Peyrusse (PRG) & 23 & 25 & 27 & 29 & 52 & 0.672 & 0.549 & 0.621 & 0.731 & 0.674 & 0.672 & 0.549 & 0.621 & 0.731 & 0.089 & 0.200 & 0.188 & 0.235 & 0.224 & 0.214 & $* *$ & $* *$ & $* * *$ & $* * * * *$ & $* * * * *$ & 0.430 & 0.466 & 0.450 & 0.554 & 0.505 \\
\hline Condom (CDM) & 25 & 24 & 29 & 28 & 53 & 0.593 & 0.582 & 0.571 & 0.596 & 0.579 & -0.004 & 0.710 & 0.054 & 0.121 & 0.062 & 0.210 & 0.215 & 0.216 & 0.220 & 0.215 & ** & ** & $*$ & $* *$ & $* * * *$ & 0.386 & 0.442 & 0.312 & 0.399 & 0.403 \\
\hline $\begin{array}{l}\text { Lahas (LHS) } \\
\text { lat }\end{array}$ & 31 & 26 & 26 & 21 & 52 & 0.629 & 0.527 & 0.647 & 0.542 & 0.590 & 0.141 & 0.115 & 0.107 & 0.066 & 0.111 & 0.258 & 0.245 & 0.243 & 0.222 & 0.244 & $* * * *$ & $* * *$ & ** & * & $* * * * *$ & 0.526 & 0.455 & 0.446 & 0.338 & 0.435 \\
\hline venes (SVN) & 29 & 27 & 23 & 21 & 50 & 0.601 & 0.502 & 0.535 & 0.466 & 0.522 & 0.008 & -0.043 & -0.018 & $\begin{array}{l}-0.087 \\
-0.00\end{array}$ & -0.031 & 0.196 & 0.210 & 0.223 & 0.242 & 0.216 & *** & NS & ** & *** & ***** & 0.352 & 0.239 & 0.411 & 0.438 & 0.335 \\
\hline Montaut (MNT) & 32 & 32 & 29 & 29 & 61 & 0.194 & 0.272 & 0.402 & 0.563 & 0.342 & 0. & 0.241 & 0.256 & 0.202 & 0.249 & 0.419 & 0.382 & 0.364 & 0.382 & 0.374 & NS & NS & $* *$ & $* * *$ & $* *$ & 0.179 & 0.187 & 0.376 & 0.476 & 0.271 \\
\hline St Felix (SFL) & 26 & 22 & 31 & 27 & 53 & 0.283 & 0.265 & 0.025 & -0.020 & 0.093 & 0.054 & 0.065 & -0.018 & -0.020 & 0.016 & 0.248 & 0.267 & 0.278 & $\begin{array}{l}0.297 \\
0.29\end{array}$ & 0.274 & $*$ & NS & NS & NS & NS & 0.298 & 0.238 & 0.036 & $\begin{array}{l}0.011 \\
-0.011\end{array}$ & 0.129 \\
\hline & 12 & 16 & 21 & 25 & 37 & 0.545 & 0.806 & -0.128 & 0.542 & 0.540 & -0.205 & -0.138 & -0.251 & -0.213 & -0.205 & 0.295 & 0.194 & 0.322 & 0.362 & 0.278 & NS & $*$ & NS & NS & NS & -0.060 & 0.466 & -0.138 & 0.105 & 0.109 \\
\hline & 22 & 29 & 25 & 32 & 54 & 0.480 & 0.306 & 0.510 & 0.303 & 0.386 & -0.173 & -0.186 & -0.207 & -0.209 & -0.196 & 0.271 & 0.299 & 0.283 & 0.306 & 0.292 & NS & NS & NS & NS & NS & 0.220 & 0.108 & 0.253 & 0.105 & 0.171 \\
\hline SMOSREX (SMX) & 29 & 30 & 23 & 24 & 53 & 0.459 & 0.496 & 0.197 & 0.280 & 0.375 & 0.077 & 0.098 & 0.071 & 0.097 & 0.086 & 0.265 & 0.268 & 0.289 & 0.291 & 0.277 & . & $* *$ & NS & $*$ & $* * *$ & 0.332 & 0.404 & 0.154 & 0.300 & 0.312 \\
\hline
\end{tabular}

the ground stations. This is in line with the results of Wagner et al. (1999a, 2007b). Jackson (1980) recommended to use morning measurements when the soil is most likely to be in hydraulic near-equilibrium, in order to avoid the daytime decoupling. Morning observations are used in the remainder of this study, resulting in an average sampling time of three days.

For three stations, SFL, LZC and NBN, Kendall $p$-values greater than 0.05 indicate that the correlations are not significant. Roughness due to mountainous areas or sea proximity (Fig. 2) may explain this lack of significance for those stations. NBN is located close to the Mediterranean sea $(15 \mathrm{~km})$ and because of the coarse ASCAT resolution of circa $50 \mathrm{~km}$, the soil moisture retrieval is affected by the proximity of the sea. At a lesser degree, LZC is also affected by this problem and only western measurements present significant results. SFL south and east areas present hilly terrains (see Fig. 2). Only the statistical scores derived from ASCAT grid points located at the north of the site are significant. If the other grid points are removed, the scores are improved (the correlation increases). For the SVN, SMX and MNT stations, the use of all ASCAT measurements leads to significant results. However, non-significant results are found for the western, eastern and the western/northern ASCAT measurements, respectively. The presence of hilly terrains and forests may explain those results.

For the configurations associated to significant correlations, no systematic dry or wet bias is observed. The correlations range from 0.283 to 0.806 with an average of 0.583 and a standard deviation of 0.137 . The URG and LZC insitu observations present the highest correlation $(0.732$ and 0.806 , respectively, for LZC, only western measurements are considered) with the ASCAT soil moisture, and the lowest RMSE (0.182 and 0.194, respectively). The bias ranges from -0.288 to 0.252 , with an average value of -0.005 . The RMSE ranges from 0.182 to 0.376 , with an average value of 0.255 . The average Kendall $\tau$ is 0.430 . The RMSE represents the relative error of the soil moisture dynamical range.
With an observed average dynamic range of $0.24 \mathrm{~m}^{3} \mathrm{~m}^{-3}$ for the SMOSMANIA network at a depth of $5 \mathrm{~cm}$, and an average RMSE value of 0.255 , an estimate of the average error of the soil moisture retrieval is about $0.06 \mathrm{~m}^{3} \mathrm{~m}^{-3}$. This value is consistent with the estimate given by Pellarin et al. (2006) for ERS-Scat, over a region in Southwestern France.

Figure 3 presents the soil moisture retrieval time series, compared with $5 \mathrm{~cm}$ in-situ measurements for the AprilSeptember 2007 period. Full dots represent the ASCAT estimates (descending (a.m.) orbits) for the configurations associated to significant correlations, whereas empty dots are for all the values (either ascending or descending orbits) and configurations. From time to time, the soil moisture retrievals display a significant bias, nevertheless peaks and troughs are well represented.

Moreover, $m s$ is a relative measure of the soil moisture content in the first few centimetres of the soil which are sensed by C-band microwaves $(0.5-2 \mathrm{~cm})$, whereas observed data at a depth of $5 \mathrm{~cm}$ are used for comparison in this study. The upper layer of the soil is more subjected to rapid drying and rewetting and soil moisture variations in this layer are more pronounced. During a rainfall event, this can lead to a temporal shift between the time when the upper layer soil moisture increases and the time water needs to percolate to $5 \mathrm{~cm}$. This is illustrated by Fig. 4: ASCAT estimates, insitu observations (average values at the same time UTC $\pm 1 \mathrm{~h}$ ) and rainfall (average daily values) at the URG station are presented. On this figure, two cases are underlined, (1) a rainfall event leads to a high ASCAT estimate, whereas no variations occur at $5 \mathrm{~cm},(2)$ at a depth of $5 \mathrm{~cm}$, variation occurs the day after a rainfall event whereas ASCAT responds immediately to the rainfall event. Such temporal gaps can be observed for all the stations and they tend to decrease the statistical scores.

\subsection{Comparison of the anomalies}

In order to avoid seasonal effects, anomalies are calculated (Sect. 2.5). The scores on the anomalies are presented in 

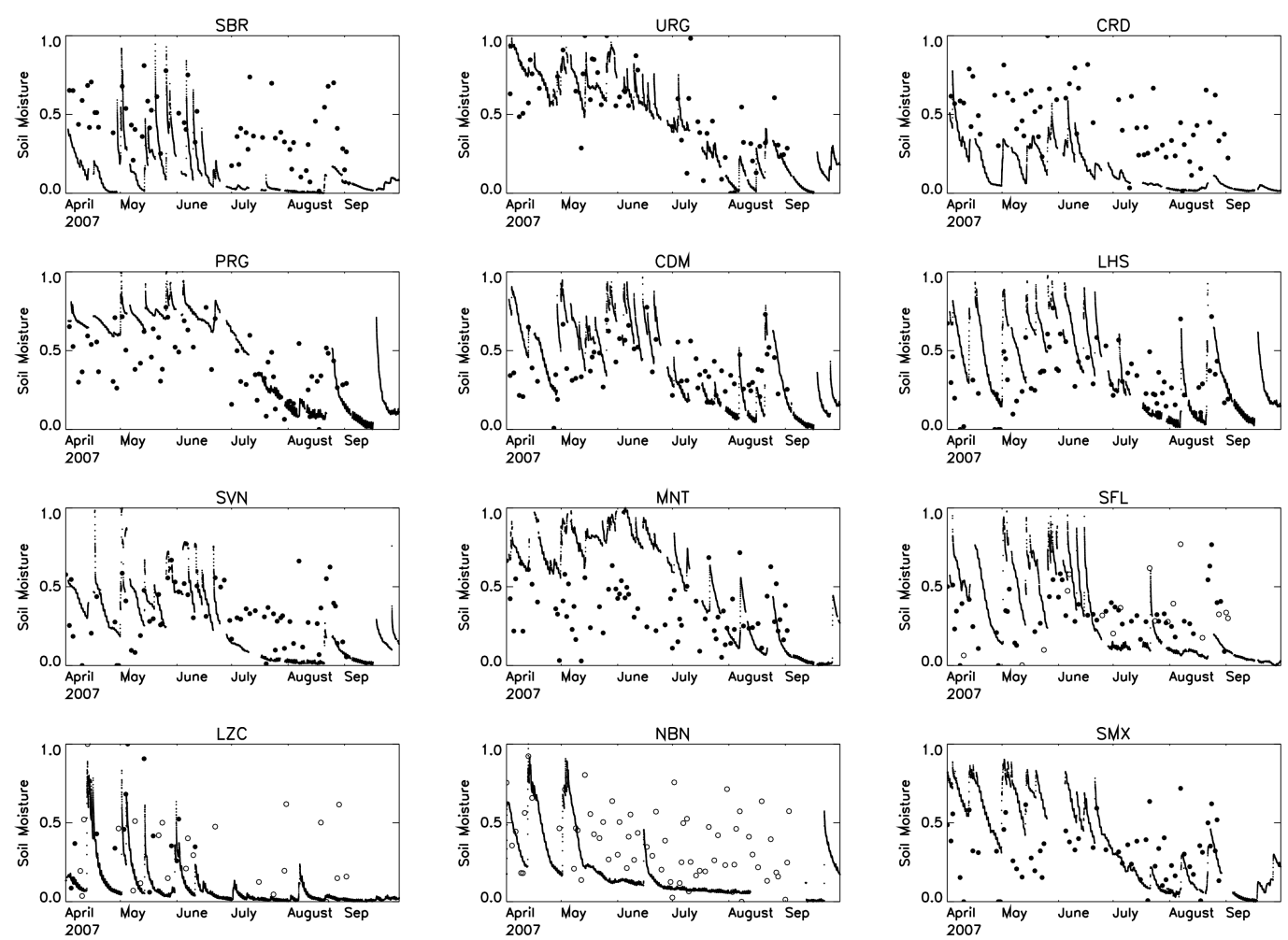

Fig. 3. Temporal evolution of ASCAT scaled surface soil moisture estimates (full and empty dots) compared to the in-situ observations at $5 \mathrm{~cm}$ for a six months period, for descending orbits between 1 April and 30 September 2007. For SFL, only the ASCAT pixels at the North of the station are considered (full dots). For LZC, only the ASCAT pixels at the West of the station are considered (full dots). Empty dots are for filtered (not used) values.

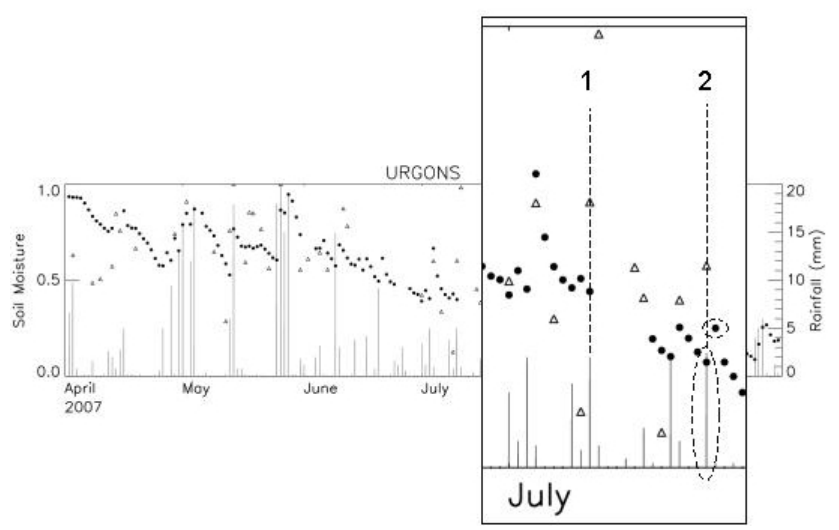

Fig. 4. Temporal evolution of the ASCAT scaled surface soil moisture (triangles) and the in-situ daily average soil moisture at $5 \mathrm{~cm}$ (dots) at the Urgons (URG) station. Vertical bars represent the daily precipitation. Two cases are highlighted: (1) a rainfall event (3 July 2007) leads to a high ASCAT value whereas no variations are detected at $5 \mathrm{~cm}$, (2) on 10 July 2007, the ASCAT soil moisture responds to a rainfall event while the in-situ soil moisture increases during the next day.
Table 2. All the available ASCAT measurements are used for the anomaly calculation. The average ASCAT vs. insitu correlation is 0.536 with a minimum and a maximum of 0.308 (URG) and 0.813 (LZC), respectively. Figure 5 presents anomaly time series derived from satellite measurements and from in-situ observations for descending (a.m.) orbits at LHS, CDM and SMX stations. Most peaks and troughs are well represented. On a six months period, seasons cannot be differentiated and a longer period would be required in order to study the seasonal variation of the scores. Anomaly correlations are as high as the correlations of the original time series. It means that the correlation is not controlled by the annual cycle.

\subsection{Correlation as a function of depth}

Correlation as a function of depth is shown in Fig. 7. For most stations, correlation decreases with depth, except for CRD and SBR. Both stations are located on sandy soils. They have the highest sand fraction of the SMOSMANIA network (Albergel et al., 2008) with an average of 885 and $937 \mathrm{~g} \mathrm{~kg}^{-1}$, respectively, along the 5 to $30 \mathrm{~cm}$ soil profile. In sandy soils, water percolates more easily and faster, which may explain the good correlation between ASCAT 
Table 2. Comparison between the normalised ASCAT and in-situ soil moisture anomaly at 11 locations for descending (morning) orbits between 1 April and 30 September 2007: correlation coefficient, bias (in-situ minus ASCAT), root mean square error (RMSE), and Kendall statistics (correlation $\tau$, and $p$-value). For SFL, only the ASCAT pixels at the North of the station are considered. For LZC, only the ASCAT pixels at the West of the station are considered.

\begin{tabular}{lcrccc}
\hline $\begin{array}{l}\text { Stations } \\
\text { names }\end{array}$ & Correlation & Bias & RMSE & $\begin{array}{c}\text { Kendall } \\
\tau\end{array}$ & $\begin{array}{c}\text { Kendall } \\
p \text {-value }\end{array}$ \\
\hline SBR & 0.542 & 0.096 & 0.877 & 0.388 & $* * * *$ \\
URG & 0.308 & 0.005 & 1.070 & 0.210 & $*$ \\
CRD & 0.369 & 0.048 & 1.102 & 0.262 & $* *$ \\
PRG & 0.451 & 0.005 & 0.912 & 0.243 & $* *$ \\
CDM & 0.593 & 0.038 & 0.841 & 0.294 & $* *$ \\
LHS & 0.808 & 0.014 & 0.717 & 0.533 & $* * *$ \\
SVN & 0.424 & -0.051 & 0.958 & 0.314 & $* * *$ \\
MNT & 0.471 & -0.021 & 0.915 & 0.314 & $* * *$ \\
SFL & 0.471 & -0.083 & 1.004 & 0.271 & $* *$ \\
LZC & 0.813 & 0.038 & 1.074 & 0.604 & $* *$ \\
SMX & 0.645 & -0.049 & 0.758 & 0.480 & $* * * *$ \\
\hline
\end{tabular}

products $(0.5-2 \mathrm{~cm})$ and $5 \mathrm{~cm}$ in-situ observations and also with deeper layers. This result is consistent with the very shallow sensing depth at C-band.

\subsection{SWI retrieval}

In a previous study (Albergel et al., 2008), the in-situ observations at $5 \mathrm{~cm}$ were used to derive the SWI for the 12 stations of the SMOSMANIA network from Eq. (3). The SWI was compared to observations at $30 \mathrm{~cm}$ and an average optimal $T$ of 6 days was found to give the best agreement for this group of stations (and also for SMOSREX). The same methodology is used in this study with ASCAT estimates. Because the upper layer $(0.5-2 \mathrm{~cm})$ of the soil is observed by ASCAT, higher $T$-value are expected. Figure 8 presents the average $r^{2}$ (based on all the stations except for MTM) as a function of $T$ (from 6 to 25 days) derived from the comparison between the retrieved SWI and in-situ observations at $30 \mathrm{~cm}$. The best average $r^{2}$ is obtained for $T=14$ days. Thus, this value is used to retrieve the SWI at each station. Results $(r$, bias and RMSE) are presented in Table 3. Average $r$, bias and RMSE are, $0.558,0.030,0.289$, respectively. One station (LZC) has a negative $r$-value $(-0.257)$. Fewer in-situ data are available at this station, and data are missing for the April to mid-July period. The highest correlation is for URG with $r=0.918$.

Correlations between the SWI and in-situ observations at $30 \mathrm{~cm}$ may be higher than the correlations between ASCAT SSM estimates and in-situ observations at $5 \mathrm{~cm}$. As mentioned in Sect. 3.1, ASCAT estimates sample a shallow (0.5$2 \mathrm{~cm}$ ) surface soil layer and some discrepancies with in-situ
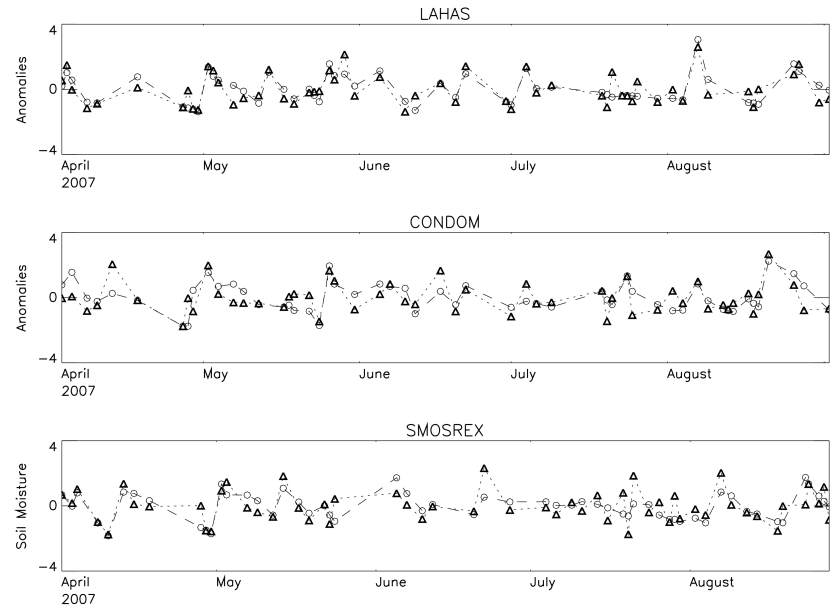

Fig. 5. Temporal evolution of surface soil moisture anomalies at two SMOSMANIA stations (LHS and CDM) and at the SMOSREX site: ASCAT (triangles) and in-situ observations at $5 \mathrm{~cm}$ (dots) for descending (a.m.) orbits between 1 April and 30 September 2007.

Table 3. Comparison of the Soil Water Index (SWI) produced by an exponential filter applied to ASCAT surface soil moisture estimates (with a characteristic time length $T$ of 14 days) with normalised insitu soil moisture observations at $30 \mathrm{~cm}$ observations at 11 locations for descending (morning) orbits between 1 April and 30 September 2007: correlation coefficient, bias (in-situ minus SWI), and root mean square error (RMSE). For SFL, only the ASCAT pixels at the North of the station are considered. For LZC, only the ASCAT pixels at the West of the station are considered.

\begin{tabular}{lrrr}
\hline Stations & Correlation & Bias & RMSE \\
\hline SBR & 0.851 & -0.145 & 0.200 \\
URG & 0.918 & 0.073 & 0.241 \\
CRD & 0.861 & -0.133 & 0.231 \\
PRG & 0.860 & -0.026 & 0.152 \\
CDM & 0.333 & 0.174 & 0.310 \\
LHS & 0.417 & 0.264 & 0.372 \\
SVN & 0.628 & 0.149 & 0.367 \\
MNT & 0.724 & 0.205 & 0.382 \\
SFL & 0.265 & 0.163 & 0.357 \\
LZC & -0.257 & -0.074 & 0.396 \\
SMX & 0.540 & -0.206 & 0.221 \\
\hline
\end{tabular}

soil moisture observations at $5 \mathrm{~cm}$ may reduce the correlation. Moreover, the profile soil moisture is less temporally variable that the surface.

\section{Conclusions}

In this paper, the first ASCAT surface soil moisture products (SSM, from the commissioning phase), delivered by EUMETSAT, covering a six month period (April to September) 

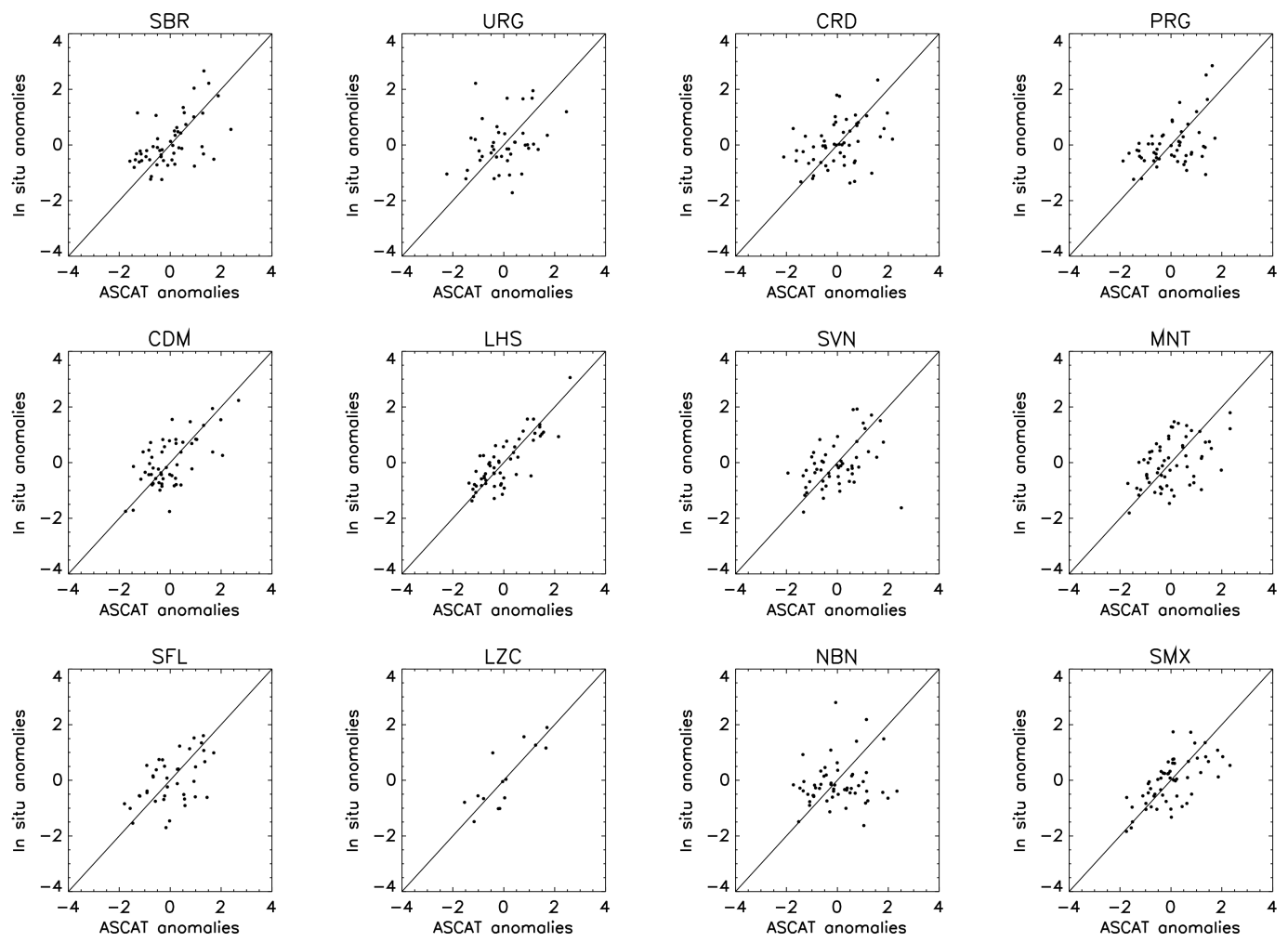

Fig. 6. In-situ surface soil moisture anomalies as a function of ASCAT anomalies (dimensionless), for descending (a.m.) orbits between 1 April and 30 September 2007. For SFL, only the ASCAT pixels at the North of the station are considered. For LZC, only the ASCAT pixels at the West of the station are considered.
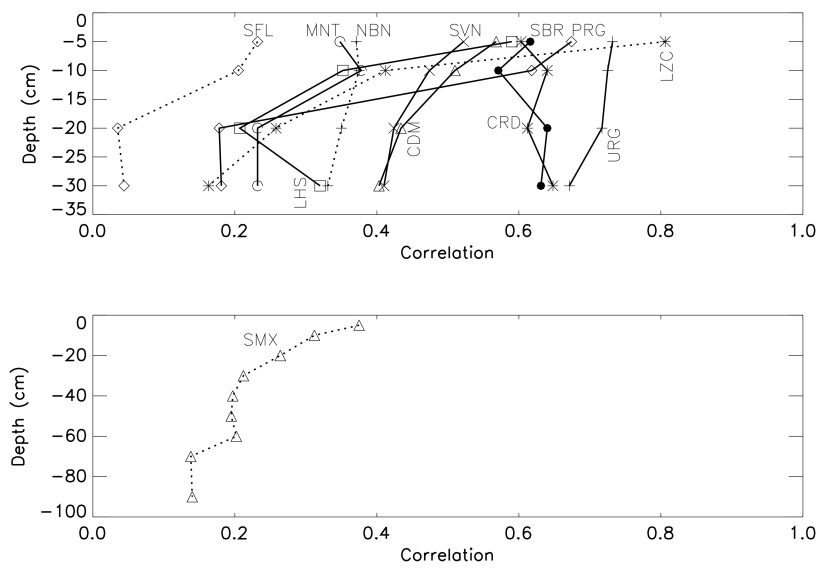

Fig. 7. Correlation coefficient between the ASCAT and the in-situ surface soil moisture anomalies as a function of depth for descending (a.m.) orbits between 1 April and 30 September 2007, for (top) SFL, MNT, BNB, SVN, CDM, LHS, CRD, SBR, PRG, URG, LZC stations, from left to right, (bottom) SMOSREX. For SFL, only the ASCAT pixels at the North of the station are considered. For LZC, only the ASCAT pixels at the West of the station are considered.

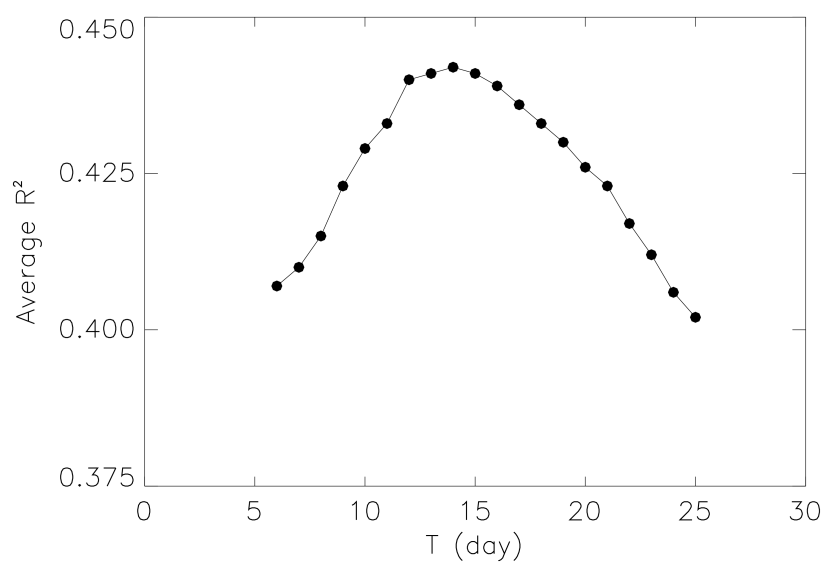

Fig. 8. Retrieval by an exponential filter of the soil water index (SWI) from the ASCAT scaled surface soil moisture product: average squared correlation coefficient $r^{2}$ of retrieved SWI versus scaled in-situ soil moisture at $30 \mathrm{~cm}$ for 11 stations in Southwestern France (10 SMOSMANIA stations and SMOSREX), as a function of the characteristic time length $(T)$ of the exponential filter. 
in 2007 are compared with in-situ data over Southwestern France. Statistical scores are calculated as a function of the location of the ASCAT pixel with respect to the station. Insitu observations at a depth of $5 \mathrm{~cm}$ for 12 stations of the SMOSMANIA network and surface soil moisture integrated from 0 to $6 \mathrm{~cm}$ at the SMOSREX station are used to evaluate ASCAT soil moisture estimates. The correlations between local (in-situ) and satellite data are encouraging and this study yields several insights on the use of the SMOSMANIA network and SMOSREX to evaluate soil moisture retrieval from remote sensing:

- 11 stations present significant correlation levels of SSM for the descending (a.m.) orbit, for all or part of the ASCAT data, with an average correlation coefficient of 0.556. Lower correlation levels are found for the ASCAT ascending (p.m.) orbits (only 4 stations are significantly correlated).

- The soil layer (5 cm depth) sampled by the SMOSMANIA in-situ observations is deeper than the top layer observed at C-band $(0.5-2 \mathrm{~cm})$ and this study shows that this difference may trigger discrepancies. In particular, a decoupling of the $0.5-2 \mathrm{~cm}$ layer with the $5 \mathrm{~cm}$ observations may develop at daytime and the quality of p.m. ASCAT SSM products may be underestimated.

- The NBN station presents no correlation with the ASCAT product and this may be caused by the proximity of this station to the Mediterranean sea.

- Relatively low anomaly correlation levels are observed for LZC and SFL stations, which are close to mountainous areas.

- A characteristic time length $(T)$ of 14 days used in an exponential filter to derive a soil water index (SWI) from ASCAT SSM measurements was found to optimize the correlation between the SWI and in-situ soil moisture observations at $30 \mathrm{~cm}$. The retrieved SWI presents good correlation with in-situ values. This method is satisfactory and relies solely on surface soil moisture estimates.

ASCAT performances are particularly interesting in data poor areas where soil moisture remotely sensed estimates may be the only measurements available. The correlation between the in-situ and satellite data highlights the potential of ASCAT and also the need to develop new soil moisture monitoring networks such as SMOSMANIA for verification in contrasting biomes and climates.

Acknowledgements. The development of the SMOSMANIA network was co-funded by Météo-France, CNES and ESA. The SMOSREX project was co-funded by the "Programme National de Télédétection Spatiale" and by the "Programme Terre Océan Surface Continentales et Atmosphère" (CNES), and by participants to the experiment: CESBIO (CNES, CNRS, IRD, UPS),
CNRM/GAME (Météo-France, CNRS), INRA, and ONERA, all in the framework of the SMOS science preparatory program. The work of C. Albergel and C. Rüdiger at CNRM is supported by CNES. The authors want to acknowledge EUMETSAT for making available ASCAT data from the commissioning phase. Finally Eric Martin and Jean-François Mahfouf (CNRM) are thanked for fruitful discussions.

Edited by: R. Ludwig

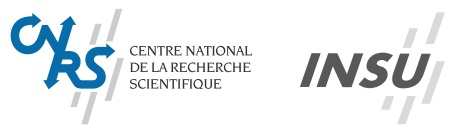

The publication of this article is financed by CNRS-INSU.

\section{References}

Albergel, C., Rüdiger, C., Pellarin, T., Calvet, J.-C., Fritz, N., Froissard, F., Suquia, D., Petitpa, A., Piguet, B., and Martin, E.: From near-surface to root-zone soil moisture using an exponential filter: an assessment of the method based on in-situ observations and model simulations, Hydrol. Earth Syst. Sci., 12, 1323-1337, 2008, http://www.hydrol-earth-syst-sci.net/12/1323/2008/.

Bartalis, Z., Wagner, W., Naeimi, V., Hasenauer, S., Scipal, K., Bonekamp, H., Figa, J., and Anderson, C.: Initial soil moisture retrievals from the METOP-A advanced Scatterometer (ASCAT), Geophys. Res. Lett., 34, L20401, doi:10.1029/2007GL031088, 2007a.

Bartalis, Z., Hasenauer, S., Naeimi, V., and Wagner, W.: WARPNRT 2.0 Reference Manual, ASCAT Soil Moisture Report Series, No.14, Institute of Photogrammetry and Remote Rensing, Vienna University of Technology, Austria, 21 pp., $2007 \mathrm{~b}$.

Calvet, J.-C., Fritz, N., Froissard, F., Suquia, D., Petitpa, A., and Piguet, B.: In-situ soil moisture observations for the CAL/VAL of SMOS: the SMOSMANIA network, International Geoscience and Remote Sensing Symposium, IGARSS, Barcelona, Spain, 1196-1199, doi:10.1109/IGARSS.2007.4423019, 23-28 July 2007.

De Rosnay, P., Calvet, J.-C., Kerr, Y., Wigneron, J.-P., Lemaître, F., et al.: SMOSREX: A long term field campaign experiment for soil moisture and land surface processes remote sensing, Remote Sens. Environ., 102, 377-389, 2006.

Gelsthorpe, R. V., Schied, E., and Wilson, J. J. W.: ASCAT-Metop's Advanced Scatteromer, ESA Bull.-Eur. Space, 102, 19-27, 2000.

Jackson, T. J.: Profile soil moisture from space measurements, J. Irr. Drain. Div.-ASCE, 106(2), 81-92, 1980.

Jackson, T. J., Hsu, A. Y., van de Griend, A., and Eagleman, J. R.: Skylab L band microwave radiometer observations of soil moisture revisited, Int. J. Remote Sens., 25, 2585-2606, 2004.

Kerr, Y., Waldteufel, P., Wigneron, J.-P., Martinuzzi, J.-M., Font, J., and Berger, M.: Soil Moisture retrieval from space: the Soil Moisture and Ocean Salinity (SMOS) mission, IEEE Trans. Geosci. Remote Sens., 39, 1729-1736, 2001.

Kerr, Y.: Soil moisture from space: Where are we?, Hydrogeol. J., 15(1), 117-120, 2007. 
Njoku, E.-G., Jackson, T. J, Lakshmi, V., Chan, T. K., and Nghiem, S. V.: Soil moisture retrieval from AMSER-E, IEEE Trans. Geosci. Remote Sens., 41(2), 215-123, 2003.

Pellarin, T., Calvet, J.-C., and Wagner, W.: Evaluation of ERS scatterometer soil moisture products over a half-degree region in Southwestern France, Geophys. Res. Lett., 33, L17401, doi:10.1029/2006GL027231, 2006.

Robock, A., Vinnikov, K. Y., Srinivasan, J. K., Entin, J. K., Hollinger, S. E., Sperenskaya, N. A., Liu, S., and Namkhai, A.: The global soil moisture data bank, B. Am. Meteorol. Soc., 81, 1281-1299, 2000.

Rüdiger, C., Hancock, G., Hemakumara, H. M., Jacobs, B., Kalma, J. D., Martinez, C., Thyer, M., Walker, J. P., Wells, T., and Willgoose, G. R.: Goulburn River experimental catchment data set, Water Resour. Res., 43, 1-10, W10403, doi:10.1029/2006WR005837, 2007.

Rüdiger, C., Calvet, J.-C., Gruhier, C., Holmes, T., De Jeu, R., and Wagner, W.: An intercomparison of ERS-Scat and AMSR-E soil moisture observations with model simulations over France, J. Hydrometeorol., in press, doi:10.1175/2008jhm997.1, 2009.

Schmugge, T. J.: Remote Sensing of Soil Moisture: Recent Advances, IEEE Trans. Geosci. Remote Sens., GE21, 145-146, 1983.
Stroud, P. D.: A recursive exponential filter for time-sensitive data, Los Alamos national Laboratory, LAUR-99-5573, http://public. lanl.gov/stroud/ExpFilter/ExpFilter995573.pdf, last access: July 2008, 1999.

Ulaby, F. T., Moore, R. K., and Fung, A. K.: Physical mechanisms and empirical models for scattering and emission, in: Microwave Remote Sensing: Active and Passive (vol. II), Artech House, Boston, MA, USA, 816-921, 1982.

Wagner, W., Lemoine, G., and Rott, H.: A method for estimating soil moisture from ERS scatterometer and soil data, Remote Sens. Environ., 70, 191-207, 1999a.

Wagner, W., Lemoine, G., Borgeaud, M., and Rott, H.: A study of vegetation cover effects on ERS scatterometer data, IEEE Trans. Geosci. Remote Sens., 37(2), 938-948, 1999b.

Wagner, W., Noll, J., Borgeaud, M., and Rott, H.: Monitoring soil moisture over the Canadian prairies with the ERS scatterometer, IEEE Trans. Geosci. Remote Sens., 37(1), 206-216, 1999c.

Wagner, W., Blöschi, G., Pampaloni, P., Calvet, J.-C., Bizzarri, B., Wigneron, J.-P., and Kerr, Y.: Operational readiness of microwave remote sensing of soil moisture for hydrologic applications, Nord. Hydrol., 38(1), 1-20, doi:10.2166/nh2007.029, 2007a.

Wagner, W., Naeimi, V., Scipal, K., Jeu, R. D., and MartinezFernàndez, J.: Soil moisture from operational meteorological satellites, Hydrogeol. J., 15, 121-131, 2007 b. 